\title{
THE EFFECT OF VENTILATION AND COOKING ACTIVITIES TOWARDS INDOOR FINE PARTICULATES IN APARTMENTS
}

\author{
Rana ZENISSA ${ }^{1}$, Arie Dipareza SYAFEI ${ }^{1,{ }^{*}}$, Usep SURAHMAN ${ }^{2}$, Alvin Christianta \\ SEMBIRING ${ }^{1}$, Alfendha Wiranditya PRADANA ${ }^{1}$, Tresta CIPTANINGAYU ${ }^{1}$, Imam \\ Safawi AHMAD ${ }^{3}$, Abdu Fadli ASSOMADI ${ }^{1}$, Rachmat BOEDISANTOSO ${ }^{1}$, Joni \\ HERMANA $^{1}$ \\ ${ }^{1}$ Department of Environmental Engineering, Faculty of Civil Engineering and Geo Engineering, Institut \\ Teknologi Sepuluh Nopember (ITS) Surabaya 6011, Indonesia. \\ ${ }^{2}$ Department of Architectural Education, Universitas Pendidikan Indonesia, Bandung 40154, \\ Indonesia. \\ ${ }^{3}$ Department of Statistics, Institut Teknologi Sepuluh Nopember (ITS) Surabaya 6011, Indonesia. \\ corresponding author: dipareza@enviro.its.ac.id.
}

\begin{abstract}
Indoor air pollution is currently being studied extensively because of its effects on the health and comfort of residents. The effects of indoor air pollution can be felt directly such as irritation to the eyes, nose to throat. This effect can also occur after several years such as respiratory infections, heart disease and cancer. Indoor air pollution such as particulate matter $\left(\mathrm{PM}_{2.5}\right.$ and $\left.\mathrm{PM}_{1}\right)$ can be caused by occupant activities such as cooking, room cleaning and smoking by residents. Research on the effect of ventilation and cooking activities on the concentration of $\mathrm{PM}_{2.5}$ and $\mathrm{PM}_{1}$ in the room has not plentiful researched. So the purpose of this study is to determine the effect of those variables in indoor air conditions. The data was obtained by measurement and interview in this study. The method that served in this research is a multilevel approach using three models. The study observes that most of the variables affected the indoor concentration of $\mathrm{PM}_{1}$ and $\mathrm{PM}_{2.5}$. In addition, it was also observed that the large number of fans could improve air quality. During peak sessions especially the morning, the number of particulates is significantly higher. Whereas cooking with an open window causes the condition of fine particulates to be even worse. Therefore, the combination of indoor pollution sources and poor outdoor concentrations has an extremely health impact on the residents. The result of the study shows the importance of adjusting the time to close the window and the time to cook properly, so that the accumulation of fine particles in the room can be avoided. Further observation is required to investigate the concentration of outdoor space near apartments continuously to confirm this result.
\end{abstract}

\author{
Keywords: \\ Indoor environmental quality; \\ Indoor pollution; \\ Fine particulates; \\ $\mathrm{PM}_{1}$; \\ $\mathrm{PM}_{2.5}$.
}

\section{Introduction}

Sick Building Syndrome (SBS) is a complaint of diseases and symptoms that are not specific, such as headaches, fatigue, skin irritation or mucous membranes of the nose and eyes and upper respiratory tract that occurs due to poor air quality in inhabited buildings caused by pollution from Volatile Organic Compound (VOC), bio-contaminants, noise and poor ventilation. Indoor air quality is one of the people's acceptance of Indoor Environmental Quality (IEQ) related to the health and comfort of residents [1].

Indoor air pollution can be caused by outdoor pollution such as dust from vehicles or industries that enter the room through ventilation. Indoor air pollutants can also be caused by burning wood, 
tobacco or candles, activities carried out at home such as smoking, furniture materials, heating, air conditioning or household cleaning products. Indoor air quality can be affected by a number of chemicals including gases, VOCs, particulates (PM), organic and inorganic contaminants and biological particles such as fungi and bacteria. Currently, there are $90 \%$ of people who spend time in an indoor environment such as home, school or office. Therefore, the condition of indoor air quality is very important in influencing human health. Another thing that can affect respiratory disease is room humidity which can become worse when there is not enough ventilation in the room and cooking activities, so there is no way out for smoke [2]. Some previous studies have shown that the mass concentration of particles in a room can be influenced by outdoor conditions. These particles can penetrate into the room because the concentration of the mass of particles outside the room is heavier. The main factor influencing this is the difference in heat or cold [3].

According to $\mathrm{WHO}$, indoor air pollution causes 1.6 million deaths due to pneumonia, chronic respiratory diseases, and lung cancer. In addition, the cause of death in developing countries is due to smoking indoors which can increase the risk of death by $3.7 \%$. Epidemiological research shows that $\mathrm{PM}_{2.5}$ can cause death, morbidity and respiratory problems. Research shows that the source of $\mathrm{PM}_{2.5}$ pollutants is obtained from cooking activities which increase the concentration of $\mathrm{PM}_{2.5}$ in the room 3.4 times. Room cleaning activities can increase $\mathrm{PM}_{2.5}$ concentrations by 3.2 times and smoking activities can increase $\mathrm{PM}_{2.5}$ concentrations up to 4.3 times [4]. Cooking can be a cause of indoor pollutants produced from hot oil, fat or from other ingredients that are cooked at high temperatures.

However, heretofore, mostly individual relationships between chemicals and health have been investigated and no comprehensive examination of the prevalence of chemicals in indoor air, in general it has been carried out. Further, in contrast to a large body of literature on IAQ and health and performance in offices, research concerning IAQ with respect to residences and home-related health issues in the general population is lacking.

Some literature shows that the condition of ventilation affects the air quality in the room. Ventilation is the process of diluting or removing pollutants in the room where clean outside air enters the room and dirty air is removed [5]. However, there are some cases where wall cracks [6] and ventilation [7] cause worse indoor pollution. Such findings are rarely discussed. This condition is suffered by the owners of houses and apartments where they live in urban areas with high concentrations of pollutants due to industrial or transportation emissions. However, in [8] was reported a higher likelihood of $\mathrm{PM}_{2.5} \mathrm{I} / \mathrm{O}$ caused by particle movement outdoors due to higher ventilation rates when outdoor concentrations are high in winter. These results are seasonal and we sought to investigate the effect of peak time sessions on how this affects indoor concentration. Challoner and Gill [9] report that ventilation does not provide significant benefits for reducing indoor pollution, even for higher $\mathrm{NO}_{2}$ gas concentrations induced by road surface concentrations. Martins and Carrilho [10] state that bad outdoor pollutants contribute to higher indoor concentrations of up to $500 \%$ in naturally ventilated, non-domestic buildings in California.

In Indonesia, research on indoor pollutants still has many shortcomings. Therefore, the researcher wants to find out the relationship between several indoor pollutant variables such as cooking time and opening windows and their relationship with indoor fine particulates.

\section{Methods}

\subsection{Data collection}

The data were collected via measurements and the interviews. The measurements consisted of the concentrations of $\mathrm{PM}_{1}$ and $\mathrm{PM}_{2.5}$. The concentrations of pollutants were collected every 10 minutes, particulate concentrations were measured via a factory-calibrated Metone Aerocet S531. Since we did not calibrate with reference-method device such as High Volume Sampler, in this paper we only focus on concentration pattern and statistical point of view. Measurements were conducted in 59 apartment units in Surabaya, and were taken from December 2017 to May 2019. The devices were put inside each main living room, but each configuration's location was adjusted so that it would not interrupt the occupant's activities and would remain safe. For each measurement, the devices were warmed up 3-5 minutes to allow them to adjust to the indoor conditions. The devices were placed on an acrylic base on a tripod at a height of \pm 1.5 meters from the floor to represent human inhalation of pollutants. Devices were set up for 24 hours to collect data at 10 minute intervals.

On average, residents of 59 apartment units have lived in their apartments for 2 years. Based on the results of interviews and questionnaires, it is known that the average number of residents in 
apartment units is 2 people with the majority being students. Most of the apartment occupants are female with an average age of 20-30 years. A small portion of the occupants of 59 apartment units are male and 7 of them smoke regularly in the room. In addition, the apartment units analyzed have an average age of 5 years and have 2 rooms in each unit.

Several variables were examined during one-on-one interviews to capture how these variables affect the pollutants' concentrations. The variables consisted of indoor conditions and inhabitants' activities, as explained in the Table 1; statistical description for each variable is explained in Table 2.

Table 1: Variables in the model input.

\begin{tabular}{|c|c|}
\hline Variables & Explanation \\
\hline Humidity (\%) & $\begin{array}{l}\text { Humidity affects pollutants' reactions indoors, and activities also affect humidity. We } \\
\text { wished to capture the relationship between humidity and pollutant's concentrations. }\end{array}$ \\
\hline Temperature $\left({ }^{\circ} \mathrm{C}\right)$ & $\begin{array}{l}\text { Indoor temperature may affect pollutants' behavior. These data were collected from the } \\
\text { device. }\end{array}$ \\
\hline $\begin{array}{c}\text { Window opening } \\
(1=\text { when window opens; } \\
0 \text { = window closes })\end{array}$ & $\begin{array}{l}\text { It is expected that when the window is open, it will allow the transfer of pollutants to the } \\
\text { outside environment. Respondent states in the questionnaire the time in which he/she } \\
\text { opens window(s) every day. We did not measure number of windows and which windows } \\
\text { opened }\end{array}$ \\
\hline $\begin{array}{c}\text { Air conditioner }(\mathrm{AC}) \text { time on } \\
\quad(1=\text { when } \mathrm{AC} \text { on; } \\
0=\text { when } \mathrm{AC} \text { off })\end{array}$ & Air conditioning lets clean air flow inside and allowing further dilution of pollutants. \\
\hline Amount of furniture & $\begin{array}{l}\text { More furniture, e.g., sofas, chairs, tables, is feared to increase the concentration of } \\
\text { pollutants, particularly particulate pollutants. }\end{array}$ \\
\hline Number of ACs & $\begin{array}{l}\text { A greater number of ACs can reduce the pollutants in the room more than a single AC } \\
\text { can. }\end{array}$ \\
\hline $\begin{array}{l}\text { Cook time } \\
(1=\text { cooking; } 0=\text { not cooking })\end{array}$ & $\begin{array}{l}\text { Cooking can increase the concentration of } \mathrm{NO}_{2} \text { and also particulates in the room. } \\
\text { Respondent states in the questionnaire the time in which he/she cooks every day. All } \\
\text { cooking activities were assumed to be done in kitchen and the distance from the device } \\
\text { was made almost equal }\end{array}$ \\
\hline Number of exhaust fans & $\begin{array}{l}\text { Exhaust fans are expected to reduce the concentration of } \mathrm{NO}_{2} \text { and particulates during } \\
\text { activities such as cooking. }\end{array}$ \\
\hline Number of fans & $\begin{array}{l}\text { The number of fans is expected to be proportional to the particulate concentrations in the } \\
\text { room. }\end{array}$ \\
\hline $\begin{array}{c}\text { Using fan } \\
(1=\text { using fan; } 0=\text { not using fan })\end{array}$ & $\begin{array}{l}\text { Using a fan can increase the flow of the indoor air and reduce the particulate } \\
\text { concentrations in the room. }\end{array}$ \\
\hline Number of bedrooms & $\begin{array}{l}\text { More bedrooms are assumed to be associated with higher particulate and TSP } \\
\text { concentrations in the room. }\end{array}$ \\
\hline
\end{tabular}

Table 2: Characteristics of apartment interior.

\begin{tabular}{|c|c|c|}
\hline Variables & Mean & SD (standard deviation) \\
\hline Humidity $(\%)$ & 62.76 & 8.1681 \\
\hline Temperature $\left({ }^{\circ} \mathrm{C}\right)$ & 29.75 & 2.0970 \\
\hline Window opening $(1=$ when window opens; 0 = window closes $)$ & 0.2498 & 0.4330 \\
\hline AC time on $(1=$ when AC on; 0 = when AC off $)$ & 0.2771 & 0.4475 \\
\hline Amount of furniture & 6.955 & 2.0064 \\
\hline Number of ACs & 1.66 & 0.8353 \\
\hline Cook time $(1=$ cook cooks; 0 not cook $)$ & 0.06346 & 0.2437 \\
\hline Number of exhaust fans & 0.8199 & 0.6251 \\
\hline Number of fans & 0.2431 & 0.4677 \\
\hline Using fan $(1=$ using fan; $0=$ not using fan) & 0.04911 & 0.2163 \\
\hline Number of bedrooms & 1.674 & 0.4765 \\
\hline
\end{tabular}

\subsection{Multilevel model}

Particulate concentration indoor in this context not only differs between time sessions but also varies within ventilation (when windows open and not). Multilevel is able to handle data which have hierarchical structures, means data are classified into groups. It also allows coefficients to vary for each group. To fully explore effect of peak sessions, ventilation and cooking activities in relation with 
$\mathrm{PM}_{1}$ and $\mathrm{PM}_{2.5}$ indoor concentrations, we run three models with following specification. All particulate concentrations are log-transformed before running.

Model 1: Original model employing all variable with varying intercept coefficient model.

Model 2: Full model employing all variables allowing cooking activities coefficient to vary by window's condition (open or not).

Model 3: A model employing all variables under the condition that only when windows were open used as the data. This model uses a varying intercept for different peak sessions (morning, evening, and non-peak).

The following Eq. 1 describes the estimation of fine particulates with varying intercept (Model 1 and 3 ) and Eq. 2 describes model in which both the intercept and the slope vary by group (coefficients of cooking activities vary by windows status: open or not) as depicted by Model 2.

$y_{i}=\alpha_{j[i]}+\beta x_{i}+\epsilon_{i}, \alpha_{j}=a+b u_{j}+\eta_{j}$,

$y_{i}=\alpha_{j[i]}+\beta_{j[i]} x_{i}+\epsilon_{i}, \alpha_{j}=a_{0}+b_{0} u_{j}+\eta_{j 1}, \beta_{j}=a_{1}+b_{1} u_{j}+\eta_{j 2}$,

$y_{i}$ - fine particulate $\left(\mathrm{PM}_{1}\right.$ and $\mathrm{PM}_{2.5}$ indoor concentration in $\mu \mathrm{g} \cdot \mathrm{m}^{-3}$ of $i$ measurement variables,

$\alpha_{j[i]}, \beta, \beta_{j[i]} X_{i}$ - unknown parameters,

$x_{i}$ - explanatory variables listed in Table 1 ,

$i$ - data observation of concentration,

[] - for (1) it refers to allowing intercept to vary by peak sessions (morning, evening, and non-peak session), whereas for (2) it reflects allowing intercepts and slopes of cooking activities vary by peak sessions. The random components be normally distributed and variances in the random components, which are assumed to be uncorrelated.

\subsection{Statistical analysis}

The models used will illustrate how the variables in Table 1 will affect the indoor concentration of $\mathrm{PM}_{1}$ and $\mathrm{PM}_{2.5}$. The window open factor is considered in the original and full model. However, there is a peak time factor in the full model, so it will be obtained three $\mathrm{PM}_{1}$ and $\mathrm{PM}_{2.5}$ concentration conditions, namely original, full and open window only.

The multilevel model is used in statistical analysis by creating scripts that will be rolled out with the $R$ software. $R$ is free software for data and graphics analysis based on the $S$ programming language developed by Rick Becker, John Chambers, and Allan Wilks from AT\&T Bell Laboratories (1976). $R$ language is a high level language (very high level language) for computing. The $R$ language allows us to calculate, view data and programs interactively with fast feedback so that it allows us to read and understand data.

\section{Results and discussion}

\subsection{Indoor concentration patterns}

Indoor concentration patterns are grouped into 3 ranges, namely $0-24 \mu \mathrm{g} \cdot \mathrm{m}^{-3}, 25-99 \mu \mathrm{g} \cdot \mathrm{m}^{-3}$, > $100 \mu \mathrm{g} \cdot \mathrm{m}^{-3}$, [11]. The presented Fig. 1 show that 59 apartment units that have the highest concentration of $\mathrm{PM}_{1}$ in the range of $0-24 \mu \mathrm{g} \cdot \mathrm{m}^{-3}$ with $66 \%$ at around $21: 00$. While the concentration of $\mathrm{PM}_{1}$ with the highest concentration of $25-99 \mu \mathrm{g} \cdot \mathrm{m}^{-3}$ with $60 \%$ at $08.00-10.00 . \mathrm{PM}_{1}$ concentrations of more than $100 \mu \mathrm{g} \cdot \mathrm{m}^{-3}$ are highest around 06.00 and 18.40 . While the average value in the room is $28.6 \mu \mathrm{g} \cdot \mathrm{m}^{-3}$.

Based on Fig. 1 it is known that the concentration that dominates $\mathrm{PM}_{1}$ in the room is between 0 $24 \mu \mathrm{g} \cdot \mathrm{m}^{-3}$ and $25-99 \mu \mathrm{g} \cdot \mathrm{m}^{-3}$. Concentrations of $0-24 \mu \mathrm{g} \cdot \mathrm{m}^{-3}$ tend to be high in the middle of the night and decrease in the morning and then increase again during the day. In contrast, $\mathrm{PM}_{1}$ concentrations in the range of $25-99 \mu \mathrm{g} \cdot \mathrm{m}^{-3}$ are high in the morning decreasing in the afternoon and returning to increase after midnight. Whereas the concentration of more than $100 \mu \mathrm{g} \cdot \mathrm{m}^{-3}$ is high in the morning and at the night. 


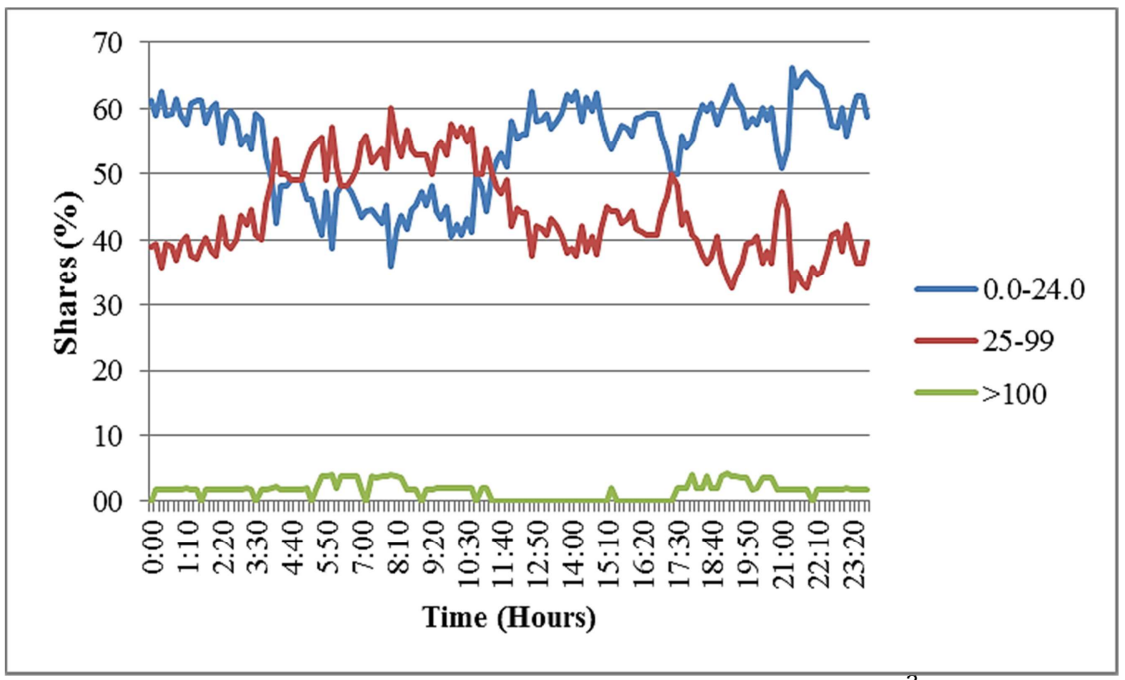

Fig. 1: Distribution of $\mathrm{PM}_{1}$ concentration $\left(\mu \mathrm{g} \cdot \mathrm{m}^{-3}\right)$.

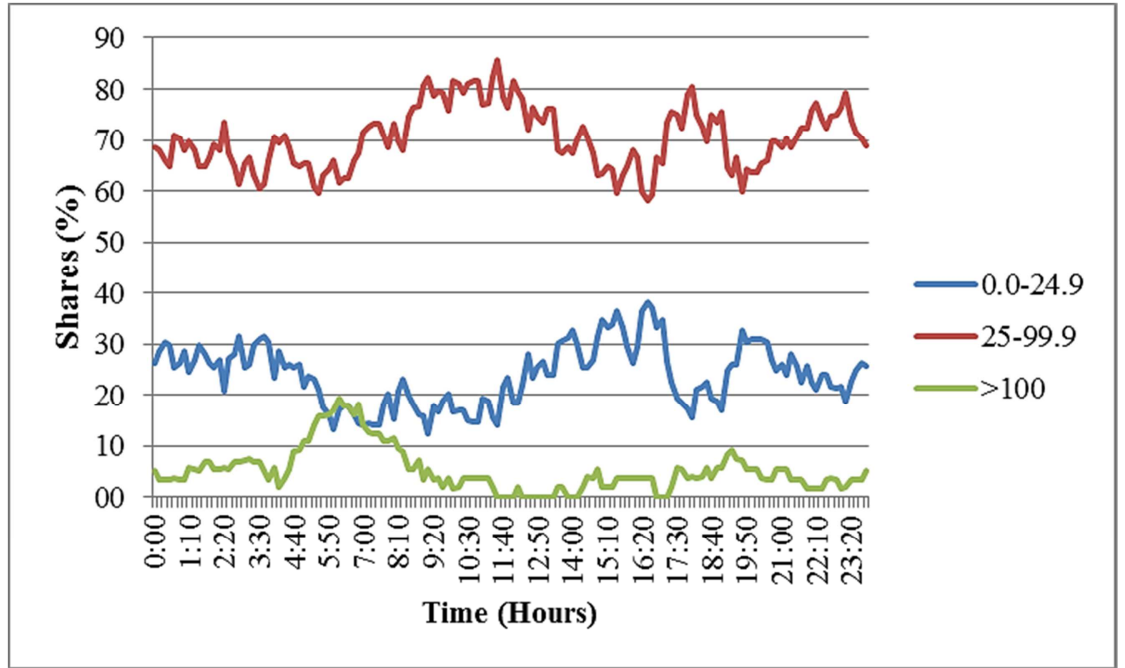

Fig. 2: Distribution of $\mathrm{PM}_{2.5}$ concentration $\left(\mu \mathrm{g} \cdot \mathrm{m}^{-3}\right)$.

Based on the Fig. 2, it can be seen that the highest $\mathrm{PM}_{2.5}$ concentration occurs at $11: 30$ am with $85 \%$ in the range of $25-99 \mu \mathrm{g} \cdot \mathrm{m}^{-3}$. The highest concentration in the range of $0-24 \mu \mathrm{g} \cdot \mathrm{m}^{-3}$ of $38 \%$ occurs at 17.00 and then decreases at the nightfall and then rises again at the night. In the range of more than $100 \mu \mathrm{g} \cdot \mathrm{m}^{-3}$ the concentration tends to be high in the morning and evening but tends to be lower in the afternoon and evening. Around $20 \%$ concentrations which are more than $100 \mu \mathrm{g} \cdot \mathrm{m}^{-3}$ are highest at $6.10 \mathrm{am}$. The presented graphs show that $\mathrm{PM}_{2.5}$ concentrations in the range of $25-99 \mu \mathrm{g} \cdot \mathrm{m}^{-3}$ tended to be more dominant in the 59 apartment units studied.

\subsection{Variables affecting indoor}

From the analysis, there are several variables that can reduce the concentration of indoor $\mathrm{PM}_{2.5}$. These variables are temperature, the use of air conditioners, the number of air conditioners, the number of fans, and the number of rooms. Apart from these variables, the concentration of $\mathrm{PM}_{2.5}$ indoor is also seen from the peak time of occupants doing activities. The peak time in this study was divided into three: the peak time in the morning (06:00 am - 10:00 am), the peak time in the afternoon $(04.00 \mathrm{pm}-07.00 \mathrm{pm})$ and non-peak time (other than the morning and evening peak times). From the results of the study found that the activity of residents in the morning can increase log odd of $\mathrm{PM}_{2.5}$ concentrations by 0.069 . Conversely, the peak time during the afternoon can actually reduce log odd of of $\mathrm{PM}_{2.5}$ by 0.089 . While the no peak time increases $\mathrm{PM}_{2.5}$ concentrations by 0.02 . The given Table 3 informs the coefficient of $\mathrm{PM}_{2.5}$ with random intercept. 
Table 3: Coefficient $\mathrm{PM}_{2.5}$ estimates with random intercept (t-value in bracket).

\begin{tabular}{|c|c|c|c|}
\hline Variables & $\mathrm{PM}_{2.5}$ Original & $\mathrm{PM}_{2.5}$ Full & $\begin{array}{l}\text { PM }_{2.5} \text { Open } \\
\text { Window }\end{array}$ \\
\hline \multicolumn{4}{|l|}{ Fixed part } \\
\hline Constant & $4.1890(29.646)$ & $4.2668(7.561)$ & $5.1406(16.858)$ \\
\hline Humidity (\%) & $0.0146(16.001)$ & $0.0145(15.863)$ & $0.0002(0.142)$ \\
\hline Temperature $\left({ }^{\circ} \mathrm{C}\right)$ & $-0.0543(-13.771)$ & $-0.0556(-14.116)$ & $-0.0512(-5.809)$ \\
\hline $\begin{array}{l}\text { Window opening }(1=\text { when window opens; } \\
0=\text { window closes })\end{array}$ & $0.06581(3.579)$ & $0.0570(0.074)$ & - \\
\hline AC time on $(1=$ when $A C$ on; $0=$ when $A C$ off $)$ & $-0.1594(-8.629)$ & $-0.1567(-8.571)$ & $-0.2722(-4.349)$ \\
\hline Number of furnitures & $0.0328(8.287)$ & $0.0310(7.771)$ & $0.0568(7.177)$ \\
\hline Number of ACs & $-0.0211(-1.905)$ & $-0.0210(-1.898)$ & $0.0096(0.410)$ \\
\hline Cooking ( 1 = cooking; 0 = not cooking) & $0.3623(12.516)$ & $0.3645(4.070)$ & $0.3931(9.196)$ \\
\hline Number of exhaust fans & $0.0078(0.666)$ & $0.0115(0.979)$ & $0.0463(1.835)$ \\
\hline Number of fans & $-0.2697(-15.673)$ & $-0.2682(-15.568)$ & $-0.2872(-5.747)$ \\
\hline Using fan ( $1=$ fan is on; $0=$ fan is off $)$ & $0.0937(2.423)$ & $0.0851(2.202)$ & $0.0167(0.268)$ \\
\hline Number of bedrooms & $-0.0171(-0.870)$ & $-0.0193 \quad(-0.983)$ & $-0.1859(-4.705)$ \\
\hline \multicolumn{4}{|l|}{ Random coefficient } \\
\hline Peak morning (intercept) & 0.0693 & & 0.0522 \\
\hline Peak evening (intercept) & -0.0894 & & -0.0964 \\
\hline Non-peak (intercept) & 0.0200 & & 0.0441 \\
\hline Window Closed: intercept & & -0.0045 & \\
\hline Window Closed: Cooking : 1 , No : 0 & & -0.0802 & \\
\hline Window Open: intercept & & 0.0045 & \\
\hline Window Open: Cooking : 1, No : 0 & & 0.0802 & \\
\hline \multicolumn{4}{|l|}{ Random part } \\
\hline Between Peak Session & 0.0068 & & 0.007712 \\
\hline Within Peak Session & 0.3630 & & 0.330073 \\
\hline Open Window & - & 0.30078 & \\
\hline Cooking within Open Window Sessioon & - & 0.01437 & \\
\hline Within Open Window Session & - & 0.36435 & \\
\hline \multicolumn{4}{|l|}{ Model performance } \\
\hline AIC & 13903.58 & 13930.87 & 3168.506 \\
\hline $\mathrm{BIC}$ & 14000.6 & 14041.76 & 3239.817 \\
\hline$-2{ }^{*}$ Loglikelihood & 13875.58 & 13898.87 & 3142.506 \\
\hline
\end{tabular}

When viewed from the cooking variables and the habit of opening a window when cooking, the variables that can reduce the concentration of $\mathrm{PM}_{2.5}$ are temperature, $\mathrm{AC}$ usage, number of air conditioners, number of fans and number of rooms. The results of the analysis show that if the occupants do activities indoors with a closed window condition, it can reduce $\mathrm{PM}_{2.5}$ concentrations by 0.004. Meanwhile, if the window is opened it can increase the concentration of $\mathrm{PM}_{1}$ in the room by 0.004. When compared to the cooking activity by closing the window $\mathrm{PM}_{2.5}$ concentrations can be reduced by 0.008 . Conversely, if the cooking activity by opening the window $\mathrm{PM}_{2.5}$ concentrations increases by 0.008 .

Several previous studies have mentioned that the increased concentration of particulates during cooking can be overcome by air ventilation. Therefore, in this study the variable opens a window compared to other variables. From the results of this study it was found that opening the window during the morning peak increases the $\mathrm{PM}_{2.5}$ concentrations by 0.05 . Instead, the $\mathrm{PM}_{2.5}$ concentrations actually drops when opening the window during the afternoon peak time. $\mathrm{PM}_{2.5}$ concentrations during the afternoon peak fell by 0.09 . Whereas at the time of non-peak $\mathrm{PM}_{2.5}$ concentration increased by 0.04 . 
The provided Table 4 gives a breakdown of coefficient $\mathrm{PM}_{1}$ with random intercept. In contrast to $\mathrm{PM}_{2.5}, \mathrm{PM}_{1}$ concentration in the room decreases due to temperature, use of air conditioners and the number of fans. Temperature, use of air conditioners and the number of fans can reduce indoor $\mathrm{PM}_{1}$ concentrations by $0.11,0.28$, and 0.17 . When viewed from peak times, just like $\mathrm{PM}_{2.5}$, the presence of occupant activity in the morning increases the concentration of $\mathrm{PM}_{1}$ in the room. During peak morning hours, the concentration of $\mathrm{PM}_{1}$ in the room increases by 0.07 . During the afternoon peak $\mathrm{PM}_{1}$ concentration decreases by 0.1 and when non-peak $\mathrm{PM}_{1}$ concentration can increase by 0.03 .

Table 4: Coefficient $\mathrm{PM}_{1}$ estimates with random intercept (t-value in bracket).

\begin{tabular}{|c|c|c|c|}
\hline Variables & $\mathrm{PM}_{1}$ Original & $\mathrm{PM}_{1}$ Full & $\begin{array}{l}\text { PM }_{1} \text { Open } \\
\text { Window }\end{array}$ \\
\hline \multicolumn{4}{|l|}{ Fixed part } \\
\hline Constant & $5.0081(34.469)$ & $4.9275(8.806)$ & $5.8089(19.586)$ \\
\hline Humidity (\%) & $0.0189(20.611)$ & $0.0187(20.386)$ & $0.0105(5.346)$ \\
\hline Temperature $\left({ }^{\circ} \mathrm{C}\right)$ & $-0.1160(-29.134)$ & $-0.1177(-29.548)$ & $-0.1287(-14.949)$ \\
\hline $\begin{array}{c}\text { Window opening }\left(\begin{array}{c}1=\text { when window opens; } 0=\text { window } \\
\text { closes })\end{array}\right. \\
\end{array}$ & $0.0367(1.974)$ & $0.3901(0.538)$ & \\
\hline$A C$ time on $(1=$ when $A C$ on; $0=$ when $A C$ off $)$ & $-0.2880(-15.405)$ & $-0.2827(-15.261)$ & $-0.4161(-6.848)$ \\
\hline Number of furnitures & $0.0377(9.579)$ & $0.0348(8.758)$ & $0.0564(7.278)$ \\
\hline Number of ACs & $0.0254(2.751)$ & 0.0254 (2.739) & $0.0297(1.545)$ \\
\hline Cooking $(1=$ cooking; $0=$ not cooking $)$ & $0.3104(10.628)$ & $0.3148(2.509)$ & $0.3781(8.983)$ \\
\hline Number of exhaust fans & $0.1454(12.455)$ & $0.1502(12.803)$ & $0.2034(8.387)$ \\
\hline Number of fans & $-0.1793(-10.602)$ & $-0.1781(-10.511)$ & $-0.2056(-4.244)$ \\
\hline Using fan ( $1=$ fan is on; $0=$ fan is off $)$ & $0.2341(6.036)$ & $0.2277(5.867)$ & $0.2474(4.082)$ \\
\hline \multicolumn{4}{|l|}{ Random coefficient } \\
\hline Peak morning (intercept) & 0.0770 & & 0.0872 \\
\hline Peak evening (intercept) & -0.1110 & & -0.0704 \\
\hline Non-peak (intercept) & 0.0340 & & -0.0167 \\
\hline Window Closed: intercept & & 0.1812 & \\
\hline Window Closed: Cooking : 1 , No : 0 & & -0.1186 & \\
\hline Window Open: intercept & & -0.1812 & \\
\hline Window Open: Cooking : 1 , No : 0 & & 0.1186 & \\
\hline \multicolumn{4}{|l|}{ Random part } \\
\hline Between Peak Session & 0.0100 & & 0.0071 \\
\hline Within Peak Session & 0.3643 & & 0.3109 \\
\hline Open Window & & 0.3287 & \\
\hline Cooking within Open Window Sessioon & & 0.0297 & \\
\hline Within Open Window Session & & 0.3661 & \\
\hline \multicolumn{4}{|l|}{ Model performance } \\
\hline AIC & 13643.99 & 13680.24 & 2959.919 \\
\hline $\mathrm{BIC}$ & 13733.82 & 13783.89 & 3025.347 \\
\hline$-2 *$ Loglikelihood & 13617.99 & 13650.24 & 2935.919 \\
\hline
\end{tabular}

When closing the window, occupant activity can increase the concentration of $\mathrm{PM}_{1}$ in the room by 0.181 conversely, if the window is opened, the concentration of $\mathrm{PM}_{1}$ in the room can be reduced. With additional activities such as cooking, $\mathrm{PM}_{1}$ concentration decreases when the window is not opened. While cooking by opening a window actually increases the concentration of $\mathrm{PM}_{1}$ in the room. From the results of the study it was found that by opening the window $\mathrm{PM}_{1}$ concentration in space during the afternoon peak and non-peak hours can decrease. Whereas during the morning peak, opening a window can even increase $\mathrm{PM}_{1}$ concentration by 0.08 .

Due to the nature of mixed effect model, we compare the performance of the three models displayed, instead of using conditional R-square. Akaike Information Criterion (AIC) gives relative 
quality of the model given set of data for both $\mathrm{PM}_{1}$ and $\mathrm{PM}_{2.5}$ data. Our last models (in Table 3 and 4) with only open window data suggest that it performs slightly better than full dataset. It indicates that our findings were confirmed showing that ventilation during peak hour, especially during morning session, caused worst indoor fine particulates.

\subsection{Household air pollutant concentration pattern distributions}

Indoor activities are highly correlated with occupant activities. Our finding reveals pattern of fine particulates during a day. $\mathrm{PM}_{2.5}$ and $\mathrm{PM}_{1}$ were observed to decrease during the afternoon peak (16.00-19.00). Whereas during the morning peak (06.00-10.00) and non-peak levels the concentration increased. Concentration increases to more than $100 \mu \mathrm{g} \cdot \mathrm{m}^{-3}$ in the morning between 6 to $8 \mathrm{pm}$ suggesting increase activities that contribute towards the increase of pollutants. These activities can be indoor and outdoor. Indoor sources are cooking and/or cleaning activities and outdoor sources may come from higher ambient level due to peak level of traffic volume.

Pollution from indoor activities were in agreement with Siddiqui, et al. [12], where they stated that the level of $\mathrm{PM}_{2.5}$ was influenced by the length of time for burning cooking fuel. Cooking using wood has a significant effect on $\mathrm{PM}_{2.5}$ concentrations. Whereas cooking using natural gas (NG) also gives the same effect although it is not significant. Ezzati et al and Dasgupta et al in Siddiqui, et al. [12] also said that cooking habits and cooking methods can increase $\mathrm{PM}_{2.5}$ concentrations and can easily spread throughout the room.

According to Frey et al. [13] high indoor $\mathrm{PM}_{2.5}$ concentrations can be influenced by occupant habits such as smoking. In the results of his study, apartment units whose residents smoked had a higher $\mathrm{PM}_{2.5}$ concentration compared to apartment units whose occupants did not smoke. While apartment units whose residents do not smoke, the high indoor $\mathrm{PM}_{2.5}$ concentrations can be caused by the use of candles, air fresheners or because of the presence of pets. But the most potential cause of high PM concentrations in the room is air fresheners.

Peak concentration takes place in the morning suggesting consistent pattern with $\mathrm{PM}_{1}$ in the morning due to occupant activities. This implies that routine daily morning activities have caused increase of indoor fine particulates. Figures also show reduction of pollutants during after $1 \mathrm{pm}$ until 4 pm suggesting that between that particulate timeframe, occupant activities were minimal or there were no occupants in the apartment.

\subsection{Household air pollutant and cooking and opening window behaviour}

Indoor concentration is highly affected by humidity and temperature as both work proportionally inverse. Our results show that for both fine PM the higher temperature tends to have less concentration, possible reason is due to formation of hygroscopic particles which leads to increase particle size thus more deposition. However, they also gave possible reason for opposite relationship. As the indoor humidity increases, there is also a chance where indoor outdoor ratio $(I / O)$ increases due to infiltration, especially when outdoor humidity is lower than indoor, allowing more penetration of particulates. The increase of humidity tends to increase concentration. This result is in agreement with Wang et al. [14] revealing that $\mathrm{PM}_{2.5}$ indoor concentrations were affected by temperature and humidity. This result is also consistent with those reported by Chithra and Nagendra [15]. This suggests that the use of dehumidifier may work well to improve indoor fine particulates.

Temperature was observed to have moderate relationship with $\mathrm{PM}_{2.5}$ and $\mathrm{PM}_{1}$ [15]. However, it must be noted that indoor temperature has diurnal pattern and different characteristics between day and night. During daylight time, indoor temperature tends to be lower than outdoor and at night indoor temperature tends to be higher than outdoor. Because of this fact, during daylight time indoor $\mathrm{PM}_{2.5}$ and $\mathrm{PM}_{1}$ concentrations tend to be higher than outdoor as a result of penetration. On the contrary, during night shift, particulates exit out the building. Our finding shows that higher temperature would reduce particulate concentrations, in which this generally occurs during night session.

Results also show that opening window tends to increase the concentration of $\mathrm{PM}_{2.5}$ and $\mathrm{PM}_{1}$ in the room. Possible reason is that higher outdoor particulate concentration entered the lower indoor concentration. Certainly many literatures stated that may ventilation reduce indoor particles, but there was lack of study for homes and apartments near high-traffic volume areas with high particulate profiles. Chang et al. [8] reported removal mechanism of $\mathrm{PM}_{10}, \mathrm{PM}_{2.5}$ and $\mathrm{PM}_{1}$ by several type of ventilation. His study revealed that ventilation remove these particulates with a note that $\mathrm{PM}_{1}$ being the most difficult one to remove. 
This finding and literatures suggests us to conclude that during high outdoor concentration it is advisable that windows were shut and during non-peak session such as early in the morning or even at the night windows can be opened for a limited time to allow fresh air displace dirty indoor air. The condition of indoor during ventilation is even worse when occupant is cooking. It is well known that cooking activities increased $\mathrm{PM}_{1}$ and $\mathrm{PM}_{2.5}$ concentrations. Cooking increase $\mathrm{PM}_{2.5}$ as it makes up to $80 \% \mathrm{PM}_{10}$ composition from cooking and it may become the main source of indoor pollution. This can happen due to emission from cooking utensils; however emission can be reduced by improving cook stoves. Hubuyo et al. [16] further elaborated that pollutant emissions from indoor cooking activities using natural gas or LPG are strongly influenced by cooking ingredients and how to cook them. Cooking by frying is known to produce fine particle concentrations with a wider range of aerodynamic sizes compared to cooking by boiling. Fine particles with a diameter of less than $2.5 \mu \mathrm{m}$ are the main particles produced in all cooking methods

To elaborate how ventilation and cooking affect indoor fine particulates, we did further investigation to explain why when the ventilation occurs and cooking takes place fine particulate concentrations are less than when the window is closed and occupants are cooking. When windows are open, outdoor particulates enters indoor and mix with inside particulates giving additional pollution that cannot be overcome by the kitchen hood. To further strengthen above assumption that particulates enter indoor, we ran another model which focuses on data when occupants are opening windows. We divide three sessions consisting of peak morning, peak evening and non-peak. Concentration in urban during peak sessions are higher due to traffic pattern although concentrations during morning have highest concentration than in the evening [17]. The possible reason is that during peak morning, since outdoor concentration tends to be higher than during non-peak session and evening session, and due to possible penetration to indoor, causing air quality becomes worse than non-peak and evening session. Syafei et al. [17] reported that parent activities to take their children to school and working commute cause this pattern. School hours are between 6.30 am to $7.15 \mathrm{am}$ whereas working hours usually starts from 7 to $9 \mathrm{am}$. On the other hand, the interval of evening session is wide. Very few schools that last until $4 \mathrm{pm}$, and not all workers go home at $4 \mathrm{pm}$. Many workers take more shifts. Therefore, the pattern distribution of evening is relatively wide unlike morning session, thus causing higher concentration in the morning. Therefore, traffic increase during morning is more centralized between 6 am to 9 am whereas during evening session, the volume increase tends to spread more. Our findings show that there is relationship between peak hours with indoor concentration.

Both $\mathrm{PM}_{1}$ and $\mathrm{PM}_{2.5}$ during open window, their concentrations tend to be higher during morning peak session. During peak evening, the concentration of outdoor is also high as result of peak traffic but not higher than during morning session. This leads us to a question: if outdoor concentration is same, then what other variables or activities that occur in morning but rarely happens in the evening. In our respondents two variables were identified, they are cooking and opening windows. For this purpose, we run varying slope and intercept multilevel model. The result confirms our concern that during opening window and at the same time occupant is cooking, $\mathrm{PM}_{2.5}$ is higher. Opening window during morning session worsen indoor $\mathrm{PM}_{2.5}$ concentrations. This fact reinforces our assumption that when outdoor concentration is high, it will enter and increase indoor concentration. Other literature did state that there is strong correlation between outdoor and indoor for fine particulates [18] even though they did not take into account inhabitant activities.

The worse of indoor particulates due to worse outdoor concentration and indoor activities shall be minimized, and several literatures had conducted research on improving indoor air. To reduce particulates from outdoor occupants may consider using air conditioner (AC) in each room. AC is widely known to have filter capability. Drawn outdoor particulates by AC will be filtered by a mechanism installed in the AC. Zhang et al. [7] stated that in the case that outdoor is polluted, an indoor particle filtration is required. AC also helps maintaining low penetration of outdoor due to its internal filtration system [19]. In the study of Singer et al. [20] stated that several combinations of mechanical ventilation and filtration can reduce the concentration of indoor particles. The use of Minimum Efficiency Report Value (MERV) filtration (MERV16) in mechanical ventilation was known to protect from outdoor particles at the lowest cost but cannot protect from particles produced indoors. Alternatively, if occupants rely on natural ventilation, they should consider to open windows not during peak morning session between 7-9 am, for each urban area, the interval may be different and therefore should be adjusted accordingly. Opening windows before 6 am is thus recommended. For indoor sources, one could consider to install air purifier to improve indoor air quality. Fans also help reducing $\mathrm{PM}_{2.5}$ and $\mathrm{PM}_{1}$, this finding is similar obtained by Guo et al. [21] implying that when fans were 
on the indoor air quality was improved. However, in this study our finding shows that when fans were on, it tends to increase particulates. The reason was that our measurements include indoor activities that may contributes more towards indoor pollution whereas Guo et al. [21] measured when there were no activities indoor or after-school hours or during weekends. The confirmation of fans roles in reducing or increasing particulates could be further explored.

The finding of this paper confirms the effect of ventilation if done without proper timing e.g. when outdoor concentration is worse than indoor. For fine particulate such as $\mathrm{PM}_{1}$, as far as author concerns, there have been no findings about it.

\section{Conclusion}

This paper examines variables that affect indoor fine particulates in apartments. We also examined the literatures on interior and inhabitant activities towards indoor quality. This paper found that most of these variables affected $\mathrm{PM}_{1}$ and $\mathrm{PM}_{2.5}$ indoor concentrations. The use of $\mathrm{AC}$ and number of fans were observed to reduce fine particulates indoor. However, we noted that the concentrations were significantly higher during morning peak session which possibly due to activity of residents in the morning and higher outdoor concentrations. Matching with many previous literatures, cooking activities increase pollutants and opening window especially during morning peak session possess even worse indoor pollution due to the accumulation of particulate infiltration (outdoor source) and emission directly from the cooking (indoor source) at the same time. Furthermore, shutting windows during peak sessions is then recommended; especially during morning peak hours, because our observation revealed less pollution under this scenario. Future research could be done to investigate effect of air changes per hour $(\mathrm{ACH})$, more indoor activities (e.g., smoking) toward fine particulates. Investigation of outdoor concentration could be conducted to strengthen the result obtained in this study.

\section{Acknowledgement}

The research was supported financially by the Directorate of Research and Community Service, Directorate General of Research and Development, Ministry of Research, Technology and Higher Education of the Republic of Indonesia under Grant No. 6/E/KPT/2019. This study was conducted with the support of Laboratory of Air Pollution Control and Climate Change in the Department of Environmental Engineering, Faculty of Civil, Environmental and Geo Engineering, Institut Teknologi Sepuluh Nopember (ITS), Surabaya, Indonesia. The authors would like to express their great appreciation and gratitude to the students in the laboratory for conducting experiments and data collection.

\section{References}

[1] LAI, A. C. K. - MUI, K. W. - WONG, L .T. - LAW, L. Y.: An evaluation model for indoor environmental quality (IEQ) acceptance in residential buildings. Energy and Buildings, 41(9), 2009, pp. 930-936, https://doi.org/10.1016/j.enbuild.2009.03.016.

[2] UPADHYAY, A. K. - SINGH, A. - KUMAR, K. - SINGH, A.: Impact of indoor air pollution from the use of solid fuels on the incidence of life threatening respiratory illnesses in children in India. BMC Public Health, 15(1), 2015, p. 300, https://doi.org/10.1186/s12889-015-1631-7

[3] WU, Y. - CHEN, C. - DU, Y. - CHEN, Z. - LI, Y.: Investigation of Indoor and Outdoor PM2.5 Pollution Situation in Beijing. Procedia Eng. 205, 2017, pp. 1223-1229. https://doi.org/10.1016/ j.proeng. 2017.10.358.

[4] SONG, P. - WANGA, L. - HUI, Y. - LI, R.: PM2.5 Concentrations Indoors and Outdoors in Heavy Air Pollution Days in Winter. Procedia Eng. 121, 2015, pp. 1902-1906, https://doi.org/10.1016/ j.proeng. 2015.09.173

[5] CHANG, T. J. - KAO, H. M. - HSIEH, Y. F.: Numerical study of the effect of ventilation pattern on coarse, fine, and very fine particulate matter removal in partitioned indoor environment. Journal of the Air and Waste Management Association, 57(2), 2007, pp. 179-189, https://doi.org/10.1080/ 10473289.2007. 10465311.

[6] LAI, A. C. K. - FUNG, J. L. S. - LI, M. - LEUNG, K. Y.: Penetration of fine particles through rough cracks. Atmospheric Environment, 60, 2012, pp. 436-443, https://doi.org/10.1016/j.atmosenv. 2012.06.053.

[7] ZHANG, T. - SU, Z. - WANG, J. - WANG, S.: Ventilation, indoor particle filtration, and energy consumption of an apartment in northern China. Building and Environment, 143, June, 2018, pp. 280-292, https://doi.org/10.1016/j.buildenv.2018.07.020. 
[8] DAI, X. - LIU, J. - LI, X. - ZHAO, L.: Long-term monitoring of indoor CO2and PM2.5 in Chinese homes: Concentrations and their relationships with outdoor environments. Building and Environment, 144, August, 2018, pp. 238-247, https://doi.org/10.1016/j.buildenv.2018.08.019.

[9] CHALLONER, A. - GILL, L.: Indoor / outdoor air pollution relationships in ten commercial buildings: PM 2.5 and NO 2. Building and Environment, 80, 2014, pp. 159-173, https://doi.org/ 10.1016/ j.buildenv.2014.05.032.

[10] MARTINS, N. R. - CARRILHO, G.: Impact of outdoor PM2.5 on natural ventilation usability in California's nondomestic buildings. Applied Energy, 189, 2017, pp. 711-724, https://doi.org/10. 1016/j.apenergy.2016.12.103.

[11] KLASEN, E. M. - WILLS, B. - NAITHANI, N. - GILMAN, R. H. - TIELSCH, J. M. - CHIANG, M. KHATRY, S. - BREYSSE, P. N. - MENYA, D. M. - APAKA, C. - CARTER, J.E. - SHERMAN, C. B. - MIRANDA, J. - CHECKLEY, W. - COCINAS TRIAL WORKING GROUP: Low correlation between household carbon monoxide and particulate matter concentrations from biomass-related pollution in three resource-poor settings. Environ. Res. 142, 2015, pp. 424-431.

[12] SIDDIQUI, A. R. - LEE, K. - BENNETT, D. - YANG, X. - BROWN, K. H. - BHUTTA, Z. A. - GOLD, E. B.: Indoor carbon monoxide and PM 2.5 concentrations by cooking fuels in Pakistan. Indoor Air 19, 2009, pp. 75-82, https://doi.org/10.1111/j.1600-0668.2008.00563.x.

[13] FREY, S. E. - DESTAILLATS, H. - COHN, S. - AHRENTZEN, S. - FRASER, M. P.: Characterization of indoor air quality and resident health in an Arizona senior housing apartment building. Journal of the Air and Waste Management Association, 64(11), 2014, pp. 1251-1259, https://doi.org/10.1080/10962247.2014.937513

[14] WANG, Z. - YU, Z.: $\mathrm{PM}_{2.5}$ and Ventilation in a Passive Residential Building. Procedia Eng. 205, 2017, pp. 3646-3653, https://doi.org/10.1016/j.proeng.2017.10.226.

[15] CHITHRA, V. S. - NAGENDRA, S. M. S.: Seasonal trends of indoor particulate matter concentrations in a naturally ventilated school building. Presented at the AIR POLLUTION 2014, Opatija, Croatia, 2014, pp. 341-351, https://doi.org/10.2495/AIR140281.

[16] HUBOYO, H. S. - TOHNO, S. - CAO, R.: Indoor $\mathrm{PM}_{2.5}$ Characteristics and CO Concentration Related to Water-Based and Oil-Based Cooking Emissions Using a Gas Stove. Aerosol Air Qual. Res. 11, 2011, pp. 401-411, https://doi.org/10.4209/aaqr.2011.02.0016.

[17] SYAFEI, A. D. - FUJIWARA, A. - ZHANG, J.: Spatial and Temporal Factors of Air Quality in Surabaya City: An Analysis based on a Multilevel Model. Procedia - Social and Behavioral Sciences, 138(0), 2014, pp. 612-622, https://doi.org/10.1016/j.sbspro.2014.07.246.

[18] CHEN, A. - GALL, E. T. - CHANG, V. W. C.: Indoor and outdoor particulate matter in primary school classrooms with fan-assisted natural ventilation in Singapore. Environmental Science and Pollution Research, 23(17), 2016, pp. 17613-17624, https://doi.org/10.1007/s11356-016-6826-7.

[19] YANG, Z. - SHEN, J. - GAO, Z.: Ventilation and Air Quality in Student Dormitories in China: A Case Study during Summer in Nanjing. Int. J. Environ. Res. Public. Health 15, 2018, p. 1328, https://doi.org/10.3390/ijerph15071328.

[20] SINGER, B. C. - DELP, W. W. - BLACK, D. R. - WALKER, I. S.: Measurement-based evaluation of ventilation and filtration systems for reducing outdoor PM2.5 in a modern California detached house. Proceedings of Indoor Air 2016, \#1124. https://www.isiaq.org/docs/Papers/Paper1124.pdf. Accessed on: $15^{\text {th }}$ September 2019.

[21] GUO, H. - MORAWSKA, L. - HE, C. - GILBERT, D.: Impact of ventilation scenario on air exchange rates and on indoor particle number concentrations in an air-conditioned classroom. Atmospheric Environment, 42(4), 2008, pp. 757-768, https://doi.org/10.1016/j.atmosenv.2007. 09.070. 